Check for updates

Cite this: RSC Adv., 2018, 8, 13159

Received 12th December 2017 Accepted 21st March 2018

DOI: 10.1039/c7ra13259

rsc.li/rsc-advances

\section{Investigation of the characteristics of concentrated leachate from six municipal solid waste incineration power plants in China}

\author{
Xu Ren, (D) Dan Liu, Weiming Chen, Guobin Jiang, Zihan Wu and Kai Song (iD *
}

The characteristics of concentrated leachate in municipal solid waste (MSW) incineration power plants were analyzed for $\mathrm{COD}_{\mathrm{Cr}}, \mathrm{BOD}_{5}$, the concentration of heavy metals, and spectral characteristics of dissolved organic matter (DOM). We performed correlation-principal component analysis to analyze the data. The samples were collected from leachate treatment plants of six MSW incineration power plants in China, all of which have a typical treatment process. Our study showed that the samples have high content of organic matter with extremely low biodegradability, various heavy metals, and a large amount of negative ions such as $\mathrm{Cl}^{-}, \mathrm{SO}_{4}{ }^{2-}$ and $\mathrm{PO}_{4}{ }^{3-}$ in the concentrated leachate. The intense fluorescent absorption peaks in the visible and ultraviolet regions of the ultraviolet-visible spectra and threedimensional fluorescence spectra suggest that the concentrated leachate contains a large amount of refractory organic matter mainly consisting of fulvic acid. The humification indexes (HIX) of samples ranged from 1.26 to 14.24 when the biodegradability indexes (BIX) ranged from 0.10 to 2.25. Correlation analysis revealed that the concentration of $\mathrm{Cl}^{-}, \mathrm{PO}_{4}{ }^{3-}$, and $\mathrm{NO}_{3}{ }^{-}$is significantly correlated with the property of the DOM, and the concentration of $\mathrm{Ca}, \mathrm{Cr}$, and $\mathrm{SO}_{4}{ }^{2-}$ almost has no correlation with other indicators in the concentrated leachate. The characteristics of the concentrated leachate are reflected by three principal components: PC1 is mainly related to the DOM, which is relatively stable and hardly degrades, this component may reflect the degradability and humification degree of the concentrated leachate. PC2 reflects the degradability of the concentrated leachate; a higher score in its positive direction indicates greater degradability of the concentrated leachate. PC3 has little influence on the characteristics of the concentrated leachate. This research can provide a theoretical basis for the effective treatment of concentrated leachate of MSW incineration power plants.

\section{Introduction}

Until 2015, the typical treatment capacity of MSWs in China is about 180 million metric tons per year, $34.4 \%$ of which is treatment by incineration. This figure is $15 \%$ higher than in 2010 (Chinese Statistical Yearbook, 2016). MSW incineration is becoming more widely used in China. The imperfect MSW classification system in China leads to the high moisture content of waste (50-60\%). To improve the calorific value of the waste, incineration power plants usually ferment the waste in a storage pit for 6-10 days. This method allows natural dehydration of the waste, but it produces much leachate at same time. Compared with the leachate of landfill, that of incineration power plants have higher concentrations of organic pollutants, and its quality and quantity fluctuates with the season. There are many techniques for treating leachate from incineration power plants. Many facilities usually adopt

Faculty of Geosciences and Environmental Engineering, Southwest Jiaotong University, No. 111, North Section 1, 2nd Ring Road, Chengdu, 610031, China. E-mail: songkailw@163.com pretreatment combined with biochemical treatment and membrane treatment. Although the effluent after treatment can meet pollutant emission standards, the membrane treatment inevitably produces large amounts of concentrated leachate, about $20-40 \%$ of the total leachate. ${ }^{1,2}$

Concentrated leachate is wastewater with high concentrations of organic substances and low biological oxygen demand $\left(\mathrm{BOD}_{5}\right) /$ chemical oxygen demand (COD) ratio. ${ }^{3-6}$ Many investigators have studied the characteristics of concentrated leachates in landfills. First, concentrated leachate has very high content of organic matter, especially humic substances (HS). The amounts of humic acid (HA) and fulvic acid (FA) range from $61.7 \%$ to $69.2 \%$, respectively. These acids are the main source of COD or TOC of the concentrated leachates in MSW landfills in Zhejiang Province. The concentration of HA is much lower than that of FA in the concentrated leachate from a refuse transfer station in Qingdao Province (China). The FA comprises $72.20 \%$ of the total HS when the HA content is $9.8 \% .^{8}$ Second, DOM in concentrated leachate has large molecular weight. The mass fraction of HA in the concentrated leachate from nanofiltration (NF) has molecular weights of $3-5 \mathrm{kDa}$ is $48.0 \%$, and that of FA 
with molecular weights of $3-10 \mathrm{kDa}$ is $33.82 \% .^{8}$ Third, concentrated leachate has high content of salt, especially chlorides and sulfates; its conductivity usually ranges from 20 to $70 \mathrm{mS} \mathrm{cm}{ }^{-1}$. After reverse osmosis (RO), the amounts of chlorides and sulfates in concentrated leachate from a landfill in Warminsko-Mazurskie Voivodeship in Poland are 1898 and $5608 \mathrm{mg} \mathrm{L}^{-1}$, respectively, and the conductivity is 8.066 $\mathrm{mS} \mathrm{cm}{ }^{-1}$.,9-12 $^{7}$ Fourth, the heavy-metal content of the concentrated leachate is extremely high. The main heavy metals are $\mathrm{Zn}$, $\mathrm{Ca}, \mathrm{Mg}$, Fe, and Cr. These metals are usually ions, and so they easily to combine with DOM, which has high molecular weight (e.g., humic acid), forming chelate. ${ }^{\mathbf{1 3}, 14}$

The technologies of MSW incineration have become more popular in China; membrane treatment technologies have developed very rapidly at the same time. However, the characteristics of the concentrated leachate from MSW incineration power plants are vastly different from that from the traditional anaerobic landfills. In addition, the physical and chemical properties of concentrated leachate vary with the region and treatment process. Studies on the molecular weight, humification degree, as well as on the characteristics of the combination of heavy metals and organic matter in DOM of the concentrated leachate from MSW incineration power plants are few.

In this work, six concentrated leachate samples were collected from MSW incineration power plants in different regions of China, namely, Shanghai, Guangzhou, Chongqing, Tianjin, Jiangxi, and Sichuan Provinces (referred to as samples A, B, C, D, E, and F, respectively). Our study analyzed the concentrations of some anions and heavy metals in samples with ion chromatography and flame atomic absorption spectrometry after measurement of $\mathrm{COD}_{\mathrm{Cr}}, \mathrm{BOD}_{5}, \mathrm{pH}$, and other indexes. We then analyzed the concentration of DOM, molecular weight, and humification degree of humus by UV-vis absorption spectroscopy and three-dimensional fluorescence technique. Lastly, we used correlations and principal component analysis to determine the relationship between the physical and chemical properties in the concentrated leachate. This paper can provide a theoretical basis and basic data for the treatment of concentrated leachate in MSW incineration power plants in China.

\section{Materials and methods}

\subsection{Sampling}

The leachate treatment processes of the six MSW incineration power plants are very common in China. These processes are shown in Fig. 1. Here, samples A, D, and E are the concentrated leachate of the first tight ultrafiltration (TU) membrane (Shanghai Jing Yu Environmental Engineering Co., Ltd.); this membrane can be used to further concentrate the NF or RO concentrated leachate to reduce the production of concentrated leachate in the power plants. Samples B and C are the concentrated leachate of the disc tube of the reverse osmosis (DTRO) membrane. Sample F is the concentrated leachate of the spiral tube (STRO) membrane. Sampling time was from December 2016 to May 2017. The samples were stored in sealed plastic drums and then analyzed on January 2017 to May 2017.

\subsection{Methods}

2.2.1 Quality analysis of the samples. Parameters of the samples such as $\mathrm{COD}_{\mathrm{Cr}}, \mathrm{BOD}_{5}, \mathrm{pH}$, total nitrogen (TN), and volatile fatty acid (VFA), were measured by conventional methods. ${ }^{15}$ We used polarized Zeeman atomic absorption spectrometry to measure the heavy-metal content of the samples, which were then digested in a nitric acid-hydrogen peroxide system. $\mathrm{Cl}^{-}$and $\mathrm{SO}_{4}{ }^{2-}$ were determined using an IC6000 ion chromatograph (WanYi, China).

2.2.2 Spectral analysis. Due to the Beer-Lambert law, the high concentration of humus in samples can affect their molar absorption coefficient, so the UV-vis absorbance and concentration will lose the linear relationship. ${ }^{\mathbf{1 6 , 1 7}}$ Therefore, the samples were filtered through a glass fiber membrane $(0.45 \mu \mathrm{m}$ pore size) and then diluted 10 times with ultrapure water prepared through two stages using a reverse-osmosis membrane. Finally, the absorbances of the concentrated leachate could be calculated by multiplying the test data of the diluted sample by 10 .

Afterward, we obtained the ultraviolet-visible absorption and fluorescence spectra on an Aqualog-UV-800C three-dimensional fluorescence spectrometer (Horiba, USA). The ultraviolet-visible absorption spectra were generated by scanning at wavelengths of 200 through $800 \mathrm{~nm}$ at $3 \mathrm{~nm}$ steps. The three-dimensional fluorescence spectra were generated by scanning at wavelengths of 239 to $650 \mathrm{~nm}$ at $3 \mathrm{~nm}$ steps and a scan rate of 2400 $\mathrm{nm} \min ^{-1}$. Here, the emission fluorescence wavelength $\left(\lambda_{\mathrm{Ex}}\right)$ was from 239 to $550 \mathrm{~nm}$, and the excitation wavelength $\left(\lambda_{\mathrm{Em}}\right)$ was from 250 to $650 \mathrm{~nm}$. Origin 8.0 (USA) was used to generate contour plots and to process the spectra.

\subsection{Data processing}

Correlation analysis and principal component analysis of the parameters in Section 2.2 used SPSS 18.0 (USA). Plotting was done using Origin 8.0.

\section{Results and discussion}

\subsection{Chemical properties of the samples}

The chemical properties of the samples are shown in Table 1. All of the samples were weakly alkaline, with $\mathrm{pH}$ values ranging from 7.56 to 8.09 , and the difference between the values is small. The $\mathrm{pH}$ of the concentrated leachate was related to the acidic or alkaline chemical reagents that were added to the front end of the leachate processing system.

The concentration of organic matter of the sample was high. The $\mathrm{COD}_{\mathrm{Cr}}$ of values ranged from 2000 to $30000 \mathrm{mg} \mathrm{L}^{-1}$. The data for the samples follow the order A $>$ E $>$ D $>$ B $>$ C $>$ F because $\mathrm{A}, \mathrm{D}$, and $\mathrm{E}$ are the concentrates of the first stage of the TU membrane. Because this membrane can further concentrate the NF concentrated leachate, the concentrate volume of the TU membrane's first stage is only $1.5 \%$ to $8 \%$ of the concentrate of the NF. Although the concentration of the organic matter is high, their $\mathrm{BOD}_{5} / \mathrm{COD}_{\mathrm{Cr}}$ ratios seem small (ranging from 0.01 to 0.09 , far less than 0.3 ), as well as the volatile fatty acid (VFA)/ $\mathrm{COD}_{\mathrm{Cr}}$ ratios (ranging only from 0.001 to 0.5 ). These data 

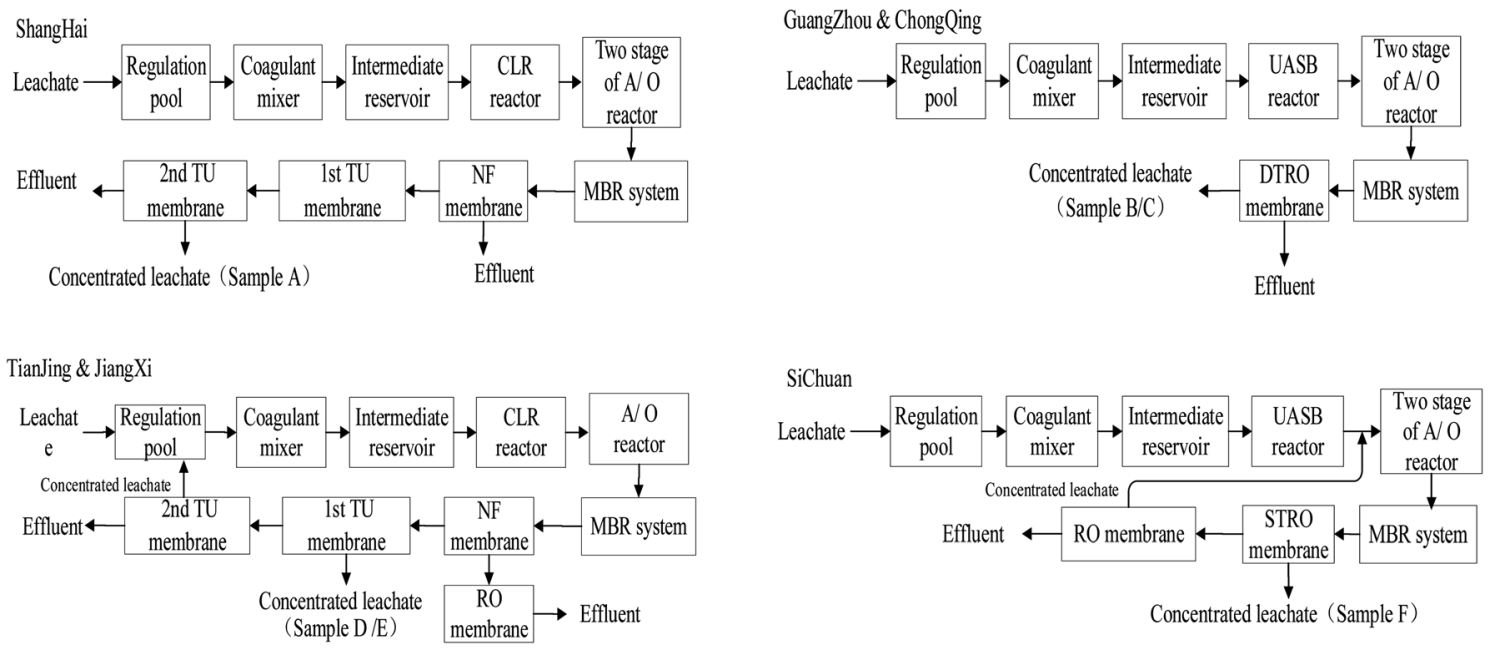

Fig. 1 Process flow diagram of landfill leachate treatment in the study.

indicate the low biodegradability of the samples; readily biodegradable fractions (such as the VFA) could be decomposed by microorganisms in aerobic or anaerobic biological reactors of the leachate treatment plant., ${ }^{7,18}$

Many of the heavy metals such as $\mathrm{Fe}, \mathrm{Zn}, \mathrm{Ni}, \mathrm{Mn}, \mathrm{Cr}, \mathrm{Al}$, and Co can be determined in the six samples. MSWs contain various heavy metals, some of which can be diluted in the leachate. The leachate contains many kinds of DOM, and DOM with large molecular weight can remain in the leachate after biochemical treatment. The molecular structures of such DOM contain many carbonyl, hydroxyl, and carboxyl functional groups, and they have strong ability to bind to heavy metals. ${ }^{19}$ These

Table 1 Chemical characteristics of the samples

\begin{tabular}{|c|c|c|c|c|c|c|}
\hline \multirow[b]{2}{*}{ Item } & \multicolumn{6}{|l|}{ Parameters } \\
\hline & $\mathrm{A}$ & B & $\mathrm{C}$ & $\mathrm{D}$ & $\mathrm{E}$ & $\mathrm{F}$ \\
\hline $\mathrm{COD}_{\mathrm{Cr}}\left(\mathrm{mg} \mathrm{L}^{-1}\right)$ & $28000 \pm 2500$ & $5000 \pm 800$ & $4500 \pm 450$ & $15000 \pm 3000$ & $22000 \pm 3400$ & $2800 \pm 700$ \\
\hline $\mathrm{BOD}_{5}\left(\mathrm{mg} \mathrm{L}^{-1}\right)$ & $950 \pm 300$ & $220 \pm 100$ & $200 \pm 85$ & $390 \pm 70$ & $850 \pm 200$ & $90 \pm 30$ \\
\hline$B / C$ & $0.04 \pm 0.02$ & $0.06 \pm 0.03$ & $0.05 \pm 0.02$ & $0.04 \pm 0.01$ & $0.05 \pm 0.02$ & $0.03 \pm 0.02$ \\
\hline $\mathrm{VFA}\left(\mathrm{mg} \mathrm{L}^{-1}\right)$ & $130 \pm 30$ & $220 \pm 30$ & $1800 \pm 300$ & $30 \pm 5$ & $400 \pm 50$ & $90 \pm 20$ \\
\hline$V / C$ & $0.005 \pm 0.002$ & $0.005 \pm 0.002$ & $0.4 \pm 0.1$ & $0.002 \pm 0.001$ & $0.18 \pm 0.04$ & $0.033 \pm 0.016$ \\
\hline $\mathrm{K}\left(\mathrm{mg} \mathrm{L}^{-1}\right)$ & $1000 \pm 200$ & $2000 \pm 350$ & $6000 \pm 700$ & $9000 \pm 850$ & $700 \pm 200$ & $1100 \pm 300$ \\
\hline $\mathrm{Na}\left(\mathrm{mg} \mathrm{L}^{-1}\right)$ & $500 \pm 80$ & $3000 \pm 500$ & $8000 \pm 1000$ & $10000 \pm 3000$ & $600 \pm 150$ & $1100 \pm 350$ \\
\hline $\mathrm{Ca}\left(\mathrm{mg} \mathrm{L}^{-1}\right)$ & $1811 \pm 301$ & $1809 \pm 818$ & $510 \pm 70$ & $1955 \pm 165$ & $1117 \pm 117$ & $890 \pm 25$ \\
\hline $\mathrm{Mg}\left(\mathrm{mg} \mathrm{L}^{-1}\right)$ & $3000 \pm 300$ & $800 \pm 150$ & $1200 \pm 200$ & $2300 \pm 300$ & $1300 \pm 250$ & $1500 \pm 200$ \\
\hline $\mathrm{Cr}\left(\mathrm{mg} \mathrm{L}^{-1}\right)$ & $0.7 \pm 0.2$ & $4.8 \pm 0.1$ & $1.6 \pm 0.4$ & $2.5 \pm 0.4$ & $1.4 \pm 0.0$ & $1.6 \pm 0.0$ \\
\hline $\mathrm{Al}\left(\mathrm{mg} \mathrm{L}^{-1}\right)$ & $1.64 \pm 0.06$ & $0.03 \pm 0.01$ & $0.04 \pm 0.01$ & $0.64 \pm 0.08$ & $0.16 \pm 0.03$ & $0.04 \pm 0.01$ \\
\hline $\operatorname{Co}\left(\mathrm{mg} \mathrm{L}^{-1}\right)$ & $0.75 \pm 0.14$ & $0.17 \pm 0.00$ & $0.40 \pm 0.05$ & $0.92 \pm 0.05$ & $0.20 \pm 0.01$ & $0.31 \pm 0.02$ \\
\hline $\mathrm{Cu}\left(\mathrm{mg} \mathrm{L}^{-1}\right)$ & $0.04 \pm 0.01$ & $0.12 \pm 0.03$ & $0.03 \pm 0.00$ & $0.03 \pm 0.00$ & $0.10 \pm 0.02$ & $0.18 \pm 0.04$ \\
\hline $\mathrm{Pb}\left(\mu \mathrm{g} \mathrm{L^{-1 }}\right)$ & 0 & $36 \pm 4$ & $9 \pm 3$ & $2 \pm 1$ & 0 & $1 \pm 0$ \\
\hline $\operatorname{Sn}\left(\mu \mathrm{g} \mathrm{L}^{-1}\right)$ & $66 \pm 5$ & $9 \pm 7$ & $25 \pm 7$ & $50 \pm 3$ & $14 \pm 9$ & $5 \pm 2$ \\
\hline $\mathrm{Hg}\left(\mu \mathrm{g} \mathrm{L}{ }^{-1}\right)$ & 0 & $0.11 \pm 0.01$ & $0.58 \pm 0.09$ & $0.21 \pm 0.09$ & $3.79 \pm 0.72$ & $0.85 \pm 0.15$ \\
\hline $\mathrm{Cl}^{-}\left(\mathrm{mg} \mathrm{L}^{-1}\right)$ & $51000 \pm 1000$ & $125000 \pm 19000$ & $129000 \pm 20000$ & $4000 \pm 3900$ & $5400 \pm 9000$ & $150000 \pm 10000$ \\
\hline $\mathrm{SO}_{4}{ }^{2-}\left(\mathrm{mg} \mathrm{L}^{-1}\right)$ & $21000 \pm 6000$ & $3000 \pm 1000$ & $24000 \pm 3000$ & $6000 \pm 900$ & $5000 \pm 300$ & $20000 \pm 4000$ \\
\hline $\mathrm{HCO}_{3}^{-}\left(\mathrm{mg} \mathrm{L}^{-1}\right)$ & $4100 \pm 300$ & $1200 \pm 180$ & $2100 \pm 110$ & $4100 \pm 100$ & $1400 \pm 140$ & $1200 \pm 70$ \\
\hline $\mathrm{PO}_{3}{ }^{4-}\left(\mathrm{mg} \mathrm{L}^{-1}\right)$ & $42 \pm 3$ & $35 \pm 1$ & $22 \pm 3$ & $5 \pm 1$ & $2 \pm 0$ & $37 \pm 3$ \\
\hline $\mathrm{CO}_{3}{ }^{2-}\left(\mathrm{mg} \mathrm{L}^{-1}\right)$ & 0 & 0 & $2060 \pm 270$ & 0 & 0 & 0 \\
\hline
\end{tabular}


combinations can be retained by the membrane and then collected in the concentrated leachate.

Table 1 also shows that the concentrations of $\mathrm{Na}$ and $\mathrm{K}$ are very high, as well as the concentration of $\mathrm{Ca}$ and $\mathrm{Mg}$. Their amounts were as high as thousands or even tens of thousands of milligrams per liter of concentrated leachate. These results indicate the high salinity and hardness of the concentrated leachate.

Their anions mainly include $\mathrm{Cl}^{-}, \mathrm{SO}_{4}{ }^{2-}, \mathrm{HCO}_{3}{ }^{-}$and $\mathrm{PO}_{3}{ }^{4-}$. Their concentration of $\mathrm{Cl}^{-}$is the highest (ranging from 4000 to $14500 \mathrm{mg} \mathrm{L}^{-1}$ ). MSWs contain abundant soluble substances such as chlorides, sulfates, orthophosphate, and bicarbonate that have large molecular structure, which causes their easy retention in the concentrate after their dissolution in the leachate.

\subsection{Spectroscopic analysis}

3.2.1 Ultraviolet-visible spectroscopic analysis. Humus always has a strong absorption in the UV and visible regions because of its aromatic and organic matter. Absorbances (Abs) at 254 and $285 \mathrm{~nm}$ are therefore often used as the parameters to estimate the concentration of humus and $\mathrm{C}=\mathrm{C}$ in aromatic substances. ${ }^{20-23}$

The UV-vis spectrum (Fig. 2) indicates that the Abs values of the DOM decreased with the increase in wavelength $(\lambda)$ and that it resembles an exponential function. Significant absorption of light can be observed in the UV range. When $\lambda$ reaches $650 \mathrm{~nm}$, the values are near zero. There is no characteristic peak in the spectrum because of the many kinds of DOM in the samples. These results are consistent with Marie's findings. ${ }^{24}$ The Abs values are higher in the UV region; accordingly, the absorption spectrum of this region is mainly due to the $\pi-\pi$ * electronic transition in the conjugated $\mathrm{C}=\mathrm{C}$ structure of the aromatic rings. ${ }^{25}$ Therefore, there were much DOM with conjugated structure, high aromaticity, and high humification degree.

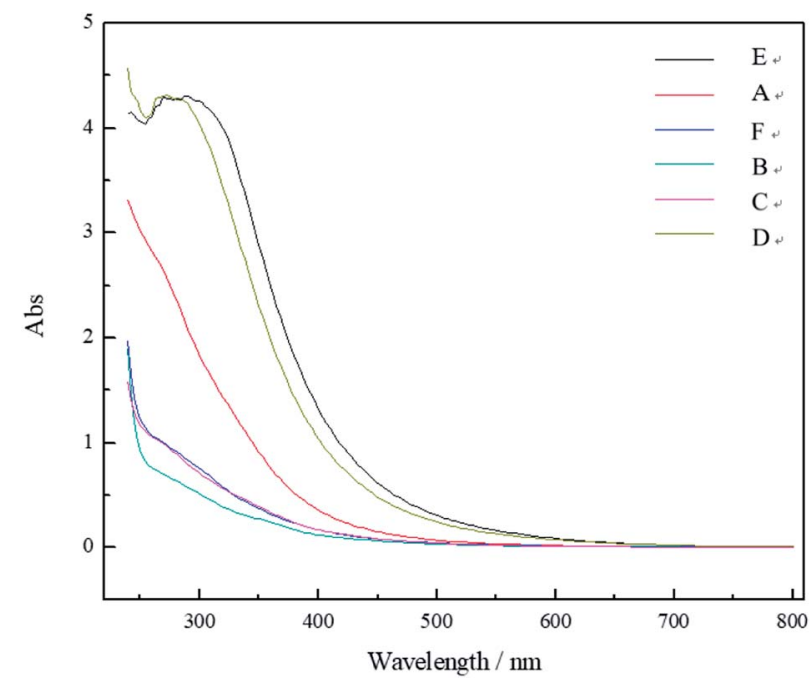

Fig. 2 UV-vis absorption spectra of the samples.
The order of the Abs values of the samples' UV-vis spectra and their DOM concentrations can be arranged as follows: $\mathrm{E}>\mathrm{D}$ $>\mathrm{A}>\mathrm{C}>\mathrm{F}>\mathrm{B}$. Since the concentrations of the samples E, D, and A were higher, their DOM concentrations were much higher than the others.

The Abs values at some characteristic wavelengths were taken to represent the physicochemical properties of the DOM. For instance, we used $E_{254}$ and $E_{280}$ (the Abs values of DOM at a unit concentration at 254 and $280 \mathrm{~nm}$, respectively) to indicate the concentration of the humus. They are directly proportional. We also used the $E_{2} / E_{3}$ ratio (the ratio of the Abs values at 250 and $365 \mathrm{~nm}$ at a unit concentration) to indicate the molecular weight of the DOM. This value is indirectly proportional to the molecular weight of the DOM. In addition, the $E_{3} / E_{4}$ and $E_{4} / E_{6}$ ratios, ${ }^{26,27}$ which are the ratios of the Abs values at unit concentration at 300 and $400 \mathrm{~nm}$ and at 465 and $665 \mathrm{~nm}$, respectively, were used to represent the molecular weight, aromaticity, and humification degree of the DOM. ${ }^{28}$ Usually, the lower is the ratio, the higher is the molecular weight, aromaticity, and humification degree of the DOM; in some cases, however, the $E_{4} / E_{6}$ ratio may not reflect the above viewpoints. ${ }^{29}$

Table 2 shows that the values of $E_{254}$ and $E_{280}$ range from 0.83 to 4.10 and from 0.63 to 4.28 . The data for samples A, D, and $\mathrm{E}$ are much larger, indicating that the humus concentration these three samples is high. Since the $E_{2} / E_{3}$ ratio of the sample $\mathrm{E}$ is the smallest, we can assume that the molecular weight of DOM in this sample is the largest. The $E_{3} / E_{4}$ ratio ranged from 3.27 to 5.27 . The data for sample A were the largest, signifying that the humification degree of the DOM in this sample is the highest. We can see that all values for B, C, and F are close, and so are those for samples $\mathrm{D}$ and $\mathrm{E}$. These indicate that the concentration, molecular weight, and humification degree of the DOM of these samples are very similar.

The similarities between these samples are related to the processing technologies of the leachate treatment system. The MSW incineration power plants in Guangzhou, Chongqing, and Sichuan adopt pretreatment, anaerobic biological treatment (in the temperature range of 30 to $40{ }^{\circ} \mathrm{C}$ ), and two-stage $\mathrm{A} / \mathrm{O}$ using an MBR, UF membrane, and RO membrane as their leachate treatment process. The treatment processes of their biochemical treatment units are similar, and they all use RO to further process the leachate. The operating mode (such as pressure) is closed, and the discharge rates of the concentrated leachate are $24 \%, 22 \%$, and $27 \%$ of total leachate, respectively. Likewise, the plants in Tianjin and Jiangxi adopt pretreatment in the leachate

Table 2 Absorbance values and the ratios of absorbance values at characteristic wavelengths

\begin{tabular}{lccccr}
\hline Item & $E_{254}$ & $E_{280}$ & $E_{2} / E_{3}$ & $E_{3} / E_{4}$ & $E_{4} / E_{6}$ \\
\hline $\mathrm{A}$ & 2.90 & 2.35 & 4.33 & 5.27 & 11.65 \\
$\mathrm{~B}$ & 0.83 & 0.63 & 4.06 & 4.39 & 7.00 \\
$\mathrm{C}$ & 1.11 & 0.89 & 3.73 & 4.23 & 10.97 \\
$\mathrm{D}$ & 4.10 & 4.27 & 2.28 & 3.96 & 11.57 \\
$\mathrm{E}$ & 4.05 & 4.28 & 1.76 & 3.27 & 14.33 \\
$\mathrm{~F}$ & 1.15 & 0.91 & 4.09 & 4.59 & 7.02
\end{tabular}


treatment process, anaerobic biological treatment (in the temperature range of 30 to $40{ }^{\circ} \mathrm{C}$ ), A/O using an MBR, UF membrane, and NF membrane, as well as two stages using TU and RO membranes. The discharge rates of concentrate of the first TU membrane of the leachate are both $1.5 \%$.

3.2.2 Fluorescence spectroscopic analysis. Spectroscopic analysis using an excitation-emission matrix (EEM) is a method that can be used to identify fluorophores with different properties through continuous scanning of excitation and emission wavelengths. ${ }^{27,30}$ This method is commonly used to characterize DOM in leachate. ${ }^{31}$ The fluorescence spectra of the samples are shown in Fig. 3 , and the analysis results are given in Table 3.

Two distinct and intense peaks can be seen in Fig. 3. One is at excitation/emission $\left(\lambda_{\mathrm{Ex}} / \lambda_{\mathrm{Em}}\right)$ wavelengths of $239-245 \mathrm{~nm}$ and 339-456 nm (peak 1), and the other is at $\lambda_{\mathrm{Ex}} / \lambda_{\mathrm{Em}}$ wavelengths of 311-335 nm and 394-419 nm (peak 2). Peak 1, which is in the UV and visible regions, is labeled as fluvic acid, which is related to carbonyl and carboxyl in humus. ${ }^{32-35}$ The substance resembling fluvic acid in the UV region is mostly from the DOM with low molecular weight and high fluorescent efficiency. It easily degrades. The substance resembling fluvic acid in the visible region appears to be aromatic; it is hardly degraded because of its large molecular weight and relatively stable structure..$^{33,36}$

Table 3 shows that the fluorescent absorption peak of the samples in the visible region $\left(I_{\mathrm{A} 2}\right)$ is more intense than are those in the UV region $\left(I_{\mathrm{A} 1}\right)$. The humification index (HIX) is large, ranging from 1.2 to 14.26 . This indicates that it has many refractory materials, and that the humification degree of the DOM in the samples is high, that is, the DOM is relatively stable. $I_{\mathrm{A} 2}$ values of samples $\mathrm{B}, \mathrm{C}$, and $\mathrm{F}$ are lower than the others because the NF concentrates in these plants were not reconcentrated. In addition, we found that the TU membrane can effectively intercept DOM with high humification degree, most which consists of large organic molecules.

The fluorescent absorption peak intensity of the samples in the $\mathrm{UV}$ region $\left(I_{\mathrm{A} 1}\right)$ of samples $\mathrm{D}$ and $\mathrm{E}$ are very low. Their $I_{\mathrm{A} 2}$ values are very high, and the biodegradability indexes (BIX) are small, only 1.00 and 1.93. These data illustrate that the concentration of substances resembling fluvic acid in the UV region is low and that the DOM in the two samples mainly consists of macromolecular humus, which is hard to degrade. In Fig. 3, we can see substances resembling fluvic acid in the visible region for samples $\mathrm{A}, \mathrm{B}, \mathrm{C}$, and $\mathrm{F}$. The humification degrees of these three samples are lower than the others. The composition differences of the six samples are due to the difference in processing efficiencies of the biochemical treatment units of the leachate treatment plants.

\subsection{Correlation and principal component analyses}

3.3.1 Correlation analysis. To reveal the relationship between the indices, we used correlation analysis, the $\mathrm{COD}_{\mathrm{Cr}}$, $\mathrm{BOD}_{5}$, VFA, heavy metals, anions at relative high concentration, and some of the spectral indicators (Fig. 4).

The results show that the concentrations of $\mathrm{Ca}$ and $\mathrm{SO}_{4}{ }^{2-}$ have no significant correlation with the other indices. The $\mathrm{pH}$ was negatively correlated with BIX, whereas COD $_{\mathrm{Cr}}$ and $\mathrm{BOD}_{5}$ had a positive correlation with $I_{\mathrm{A} 2}$.

The concentration of $\mathrm{Mg}, \mathrm{Zn}, \mathrm{Ni}$, and $\mathrm{Co}$ has a positive correlation with the concentration of $\mathrm{HCO}_{3}{ }^{-}$. The concentration of the heavy metal Fe was highly correlated with the $E_{2} / E_{3}$ ratio and HIX. The greater was the Fe content, the larger was the molecular weight and the higher was the humification degree of the DOM.
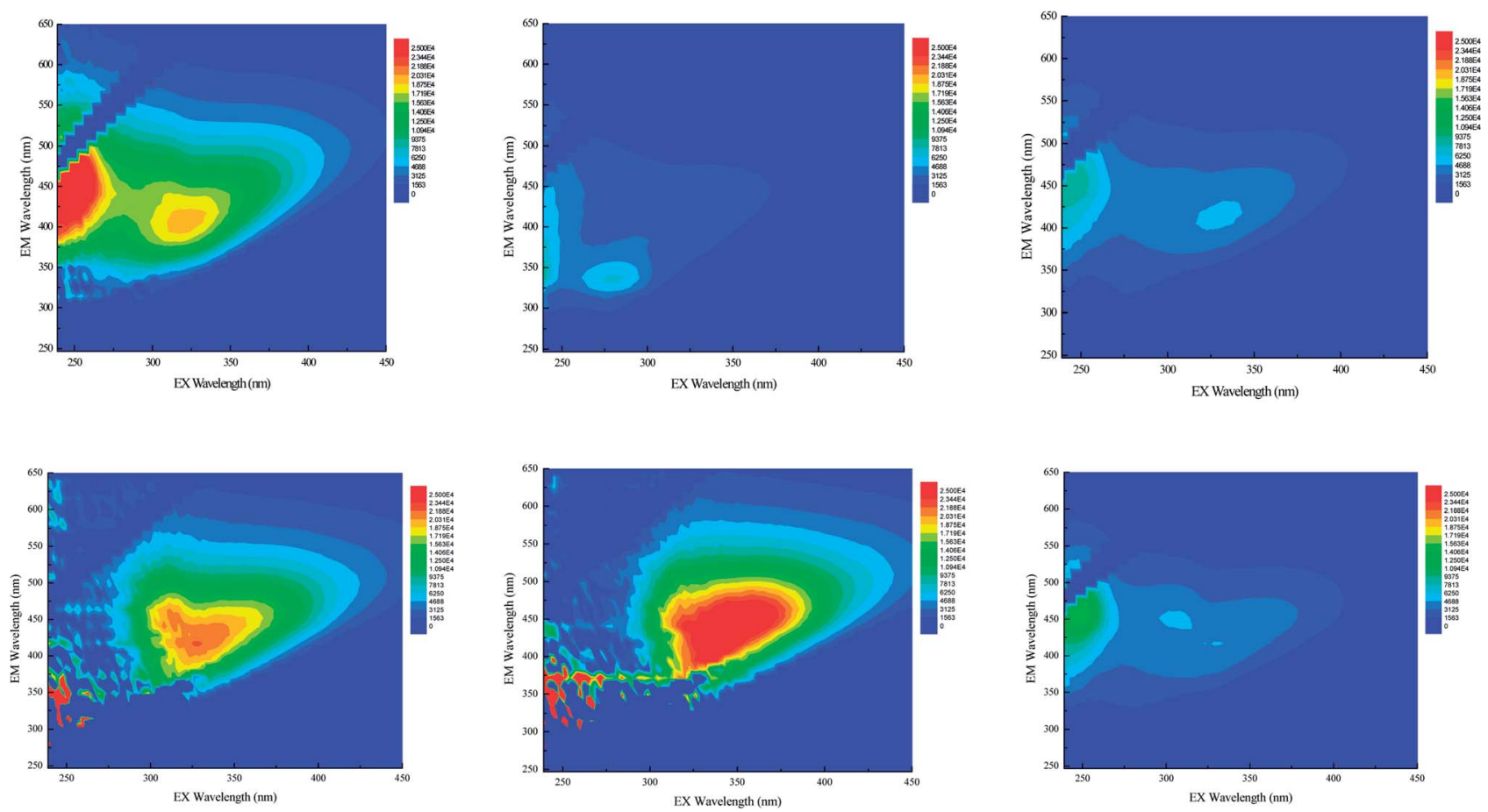

Fig. 3 Three-dimensional fluorescence spectra of the six samples. 
Table 3 Results of the analysis of the 3D fluorescence spectra of the six samples

\begin{tabular}{llllrlll}
\hline Item & Peak 1 & $I_{\mathrm{A} 1}$ & Peak 2 & \multicolumn{1}{c}{$I_{\mathrm{A} 2}$} & HIX & BIX & $I_{\mathrm{A} 1} / I_{\mathrm{A} 2}$ \\
\hline $\mathrm{A}$ & $248 / 456$ & 36866.47 & $323 / 407$ & 19812.01 & 8.22 & 2.19 & 0.54 \\
$\mathrm{~B}$ & $239 / 339$ & 10438.81 & $311 / 394$ & 3046.72 & 1.26 & 2.25 & 0.29 \\
$\mathrm{C}$ & $245 / 454$ & 9257.13 & $329 / 410$ & 5007.29 & 7.46 & 1.37 & 0.54 \\
$\mathrm{D}$ & - & - & $326 / 410$ & 22457.89 & - & 1.93 & - \\
$\mathrm{E}$ & - & - & $335 / 419$ & 29113.18 & - & 1.00 & - \\
$\mathrm{F}$ & $248 / 456$ & 15914.95 & $323 / 417$ & 4694.92 & 14.24 & 1.95 & 0.30
\end{tabular}

The concentration of the $\mathrm{Cl}^{-}$was negatively correlated with $\mathrm{COD}_{\mathrm{Cr}}, E_{254}, E_{280}$, and $I_{\mathrm{A} 2}$; the concentration of $\mathrm{PO}_{4}{ }^{3-}$ had a positive correlation with the $E_{2} / E_{3}$ ratio, $E_{3} / E_{4}$ ratio, $I_{\mathrm{A} 1}$, and HIX. In addition, the concentration of $\mathrm{NO}_{3}{ }^{-}$had a negative correlation with the $E_{4} / E_{6}$ ratio. These indices represent the composition and content of the DOM and the humification degree. Hence, the concentration of $\mathrm{Cl}^{-}, \mathrm{PO}_{4}{ }^{3-}$, and $\mathrm{NO}_{3}{ }^{-}$has a significant correlation with the characteristics of DOM in the concentrated leachate.

There were also some correlations between the optical indicators: $E_{254}$ had a high positive correlation with $E_{280}$, the $E_{4} /$ $E_{6}$ ratio, $I_{\mathrm{A} 2}$, and HIX. $E_{280}$ was positively correlated with $E_{254}$, and $I_{\mathrm{A} 2}$, and it was negatively correlated with the $E_{2} / E_{3}$ ratio. There was a positive correlation between the $E_{2} / E_{3}$ and $E_{3} / E_{4}$ ratios, as well as between the $E_{4} / E_{6}$ ratio and $I_{\mathrm{A} 2}$.
3.3.2 Principal component analysis. Fig. 5 reveals the principal component (PC) analysis results for the indices. They show that the cumulative variance of the first (PC1), second (PC2), and third (PC3) principal components is $81.53 \%$, and their variance contribution rates are $39.45 \%, 27.45 \%$, and $14.62 \%$, respectively.

The variance contribution rate of PC1 is the largest. For this, $E_{254}, E_{280}$, and $I_{\mathrm{A} 2}$ had a positive effect when the horizontal load exceeded 0.92. The concentrations of $\mathrm{Cl}^{-}$and $\mathrm{NO}_{3}{ }^{-}$had a negative effect when the horizontal load exceeded -0.84 . Thus, PC1 is mainly related to the DOM, which is stable and hard to degrade, and PC1 may reflect the degradability and humification degree of the concentrated leachate.

The concentration of $\mathrm{Zn}$, the $E_{3} / E_{4}$ ratio, $I_{\mathrm{A} 1}$, and BIX mainly affected PC2, and their horizontal load exceeded 0.80. The $E_{3} /$ $E_{4}$ ratio and $I_{\mathrm{A} 1}$ reveal the molecular weight and the humification degree of DOM. Thus, the high score in the positive direction of PC2 indicates that the concentrated leachate easily degrades.

The concentration of $\mathrm{NH}_{4}{ }^{+}-\mathrm{N}$ and VFA has higher horizontal load in PC3, reaching 0.90 and 0.84 , relatively. The others indices have much lower horizontal load; therefore, these indices for PC3 have little influence on the characteristics of DOM in the concentrated leachate.

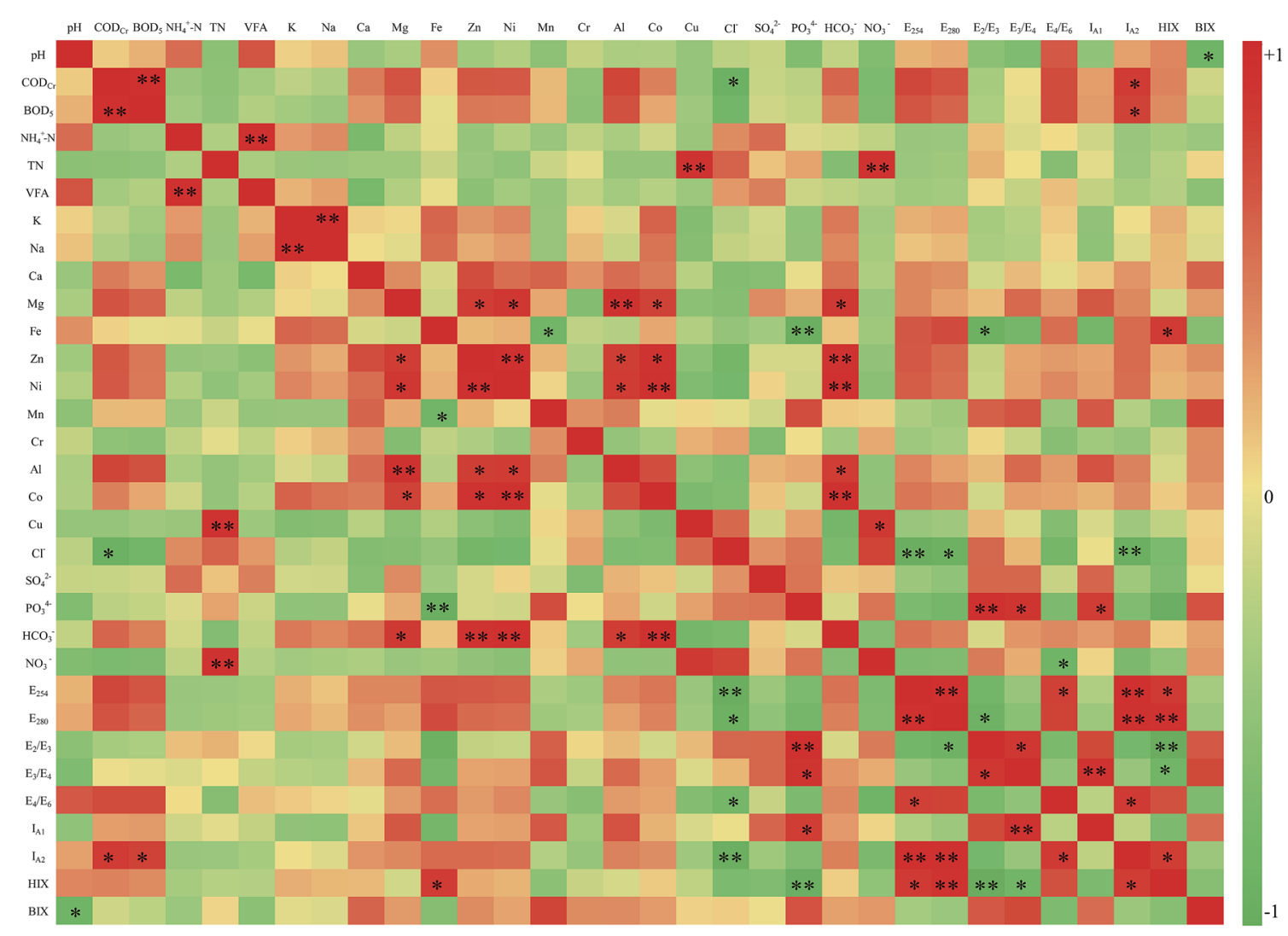

Fig. 4 Correlation heat map for the indices. Note: * and ** indicate significant correlations at $p<0.05$ and $p<0.01$, respectively. 


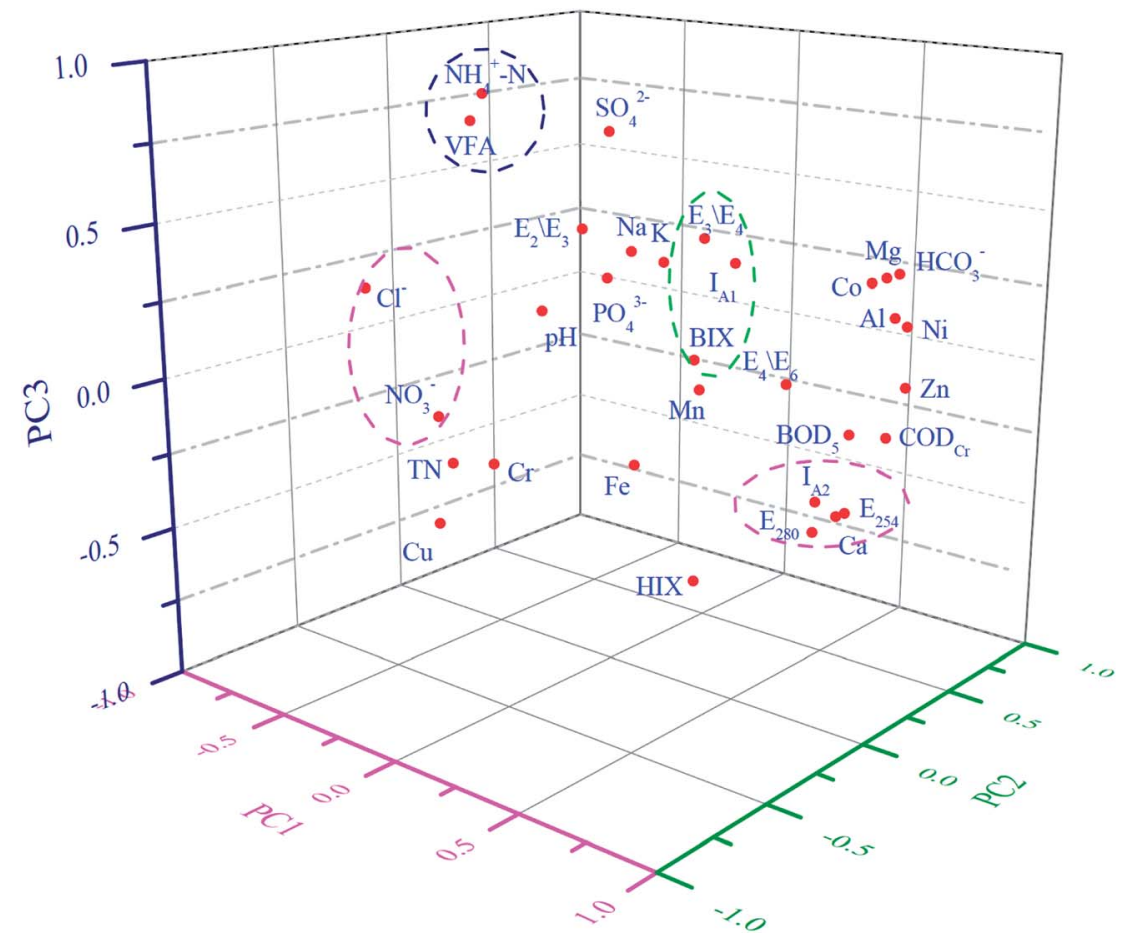

Fig. 5 Scatter plot of factor loads of the samples.

\subsection{Prospects for the engineering application of the results}

The concentrated leachate had extremely low biodegradability because of its considerable amount of DOM with large molecular weight. Innocent treatment of the concentrated leachate is needed to degrade this DOM thoroughly. However, most of the MSW incineration power plants in China have no economic resources to equipped precision instruments such as ultraviolet-visible spectrometers and three-dimensional fluorescence spectrometers. Without such equipment, incineration power plants have to send the samples to other labs that are better equipped. But if the analysts want to have a preliminary evaluation of the treatment effect of the concentrated leachate, especially the removal rate of the macromolecular DOM, in a short time, they could analyze the concentration of $\mathrm{Fe}, \mathrm{Cl}^{-}, \mathrm{NO}_{3}{ }^{-}$, and $\mathrm{PO}_{4}{ }^{3-}$ by chemical titration after simple processing of the sample. For instance, higher concentrations of $\mathrm{Cl}^{-}$and $\mathrm{PO}_{4}{ }^{3-}$ or/and lower concentrations of $\mathrm{Fe}$ and $\mathrm{NO}_{3}{ }^{-}$result in better treatment effect after processing.

\section{Conclusions}

(1) The high concentration of organic substances in the concentrated leachate, and the biodegradability is extremely low. The concentrated leachate contains high levels of heavy metals, $\mathrm{Cl}^{-}$, and $\mathrm{SO}_{4}{ }^{2-}$ because of the integration of the NF or the RO membrane.

(2) The UV-vis spectrum of the concentrated leachate resembles an exponential function, indicating high levels of DOM with high humification degree in the concentrated leachate. The processing of the concentrated leachate is related to the Abs values at some characteristic wavelengths and their ratios. The 3D fluorescence spectrum shows a large amount of refractory materials in the concentrated leachate of the samples. The fluorescence absorption peaks have high intensities $\left(\lambda_{\mathrm{Ex}} / \lambda_{\mathrm{Em}}\right.$ ratios of 311-335 $\mathrm{nm}$ and 394-419 $\mathrm{nm}$ ).

(3) Correlation analysis revealed that the concentration of $\mathrm{Mg}$ and $\mathrm{Cl}^{-}$is significantly correlated with the property of the DOM, and that VFA, BIX, and the concentration of $\mathrm{Ca}$ has almost no correlation with other indicators in the concentrated leachate.

(4) Three principal components from principal component analysis indicate the characteristics of the concentrated leachate. PC1 is related to the DOM, which is relatively stable and hard to degrade. This component always reflects the degradability and humification degree of the concentrated leachate. PC2 can also reflect the degradability of the concentrated leachate; a higher score in its positive direction indicates that the leachate is more likely to degrade. PC3 has weak correlation with the nature of the concentrated leachate.

(5) Analysts of MSW incineration power plants may determine the treatment effect of the concentrated leachate, especially the removal rate of the macromolecular DOM, by titrimetric analysis of the concentrations of $\mathrm{Fe}, \mathrm{Cl}^{-}, \mathrm{NO}_{3}{ }^{-}$, and $\mathrm{PO}_{4}{ }^{3-}$ of a sample before and after processing.

\section{Conflicts of interest}

There are no conflicts to declare. 


\section{Acknowledgements}

This research was supported by the Foundation of Feasibility Study Report of Concentrated Leachate Spraying into Incinerator, Environmental Protection Agency of Sichuan Province, China (Y17018), the Foundation of Key Laboratory of Special Waste Water Treatment, Sichuan Province Higher Education System (SWWT2015-4).

\section{References}

1 B. Ozkaya, J. Hazard. Mater., 2015, 124(1), 107-112.

2 Y. Dang, Y. Q. Lei and Z. Liu, Water Res., 2016, 106, 71-78.

3 S. Top, E. Sekman, S. Hoșver and M. Sina Bilgili, Desalination, 2011, 268, 158-162.

4 B. Zhou, Z. M. Yu, Q. P. Wei, H. Y. Long, Y. M. Xie and Y. J. Wang, Appl. Surf. Sci., 2016, 377, 406-415.

5 R. He and X. M. Wei, Waste Manag., 2015, 08(6), 380-388.

6 V. B. Bruggen, L. Lejon and C. Vandecasteele, Environ. Sci. Technol., 2003, 137(17), 3733-3738.

7 Q. Q. Zhang, B. H. Tian, X. Zhang, A. Ghulam, C. R. Fang and

R. He, Waste Manage., 2013, 33, 2277-2286.

8 G. W. Li and Q. Zhang, Environ. Eng., 2016, 6, 31-34.

9 F. N. Ahmed and C. Q. Lan, Desalination, 2012, 287, 41-54.

10 Y. Wang and X. Li, J. Hazard. Mater., 2012, 229-230, 115-121. 11 I. A. Talalaj and P. Biedka, Ecol. Eng., 2015, 85, 185-192.

12 Y. Y. Long, J. Xu, D. S. Shen, Y. Du and H. Feng, Chemosphere, 2017, 167, 512-519.

13 Z. Tasiaa, Adv. Environ. Res., 2002, 6, 207-208.

14 S. Irem and T. O. Turgut, J. Hazard. Mater., 1996, 5, 259-260. 15 APHA, AWWA and WEF, American Public Health

Association, Washington, DC, 2005.

$16 \mathrm{X}$. He and B. Xi, Chemosphere, 2011, 82, 541-548.

17 X. J. Guo and X. S. He, Microchem. J., 2012, 102, 115-122.
18 Y. S. Gilber, J. Chang, T. A. Kurniawan, C. X. Fu, H. Jiang and J. Ying, Desalination, 2007, 202, 310-317.

19 G. Aiken and J. Leenheer, Chem. Ecol., 1993, 8(3), 135-151.

20 S. J. Traina, J. Novak and N. E. Smeck, Environ. Qual., 1990, 19, 151.

21 B. Gu, J. Schmitt, Z. Chen, L. Liang and J. F. McCarthy, Geochim. Cosmochim. Acta, 1995, 59, 217-220.

22 K. Ghosh and M. Schnitzer, Soil Sci., 1979, 30, 734-736.

23 M. G. Fuentes, G. Gaitano and J. M. Mina, Org. Geochem., 2016, 37(12), 1949-1959.

24 L. Marie, B. Pernet-Coudrier, M. Waeles, M. Gabon and R. Riso, Sci. Total Environ., 2015, 537, 23-32.

25 D. Trebouet, J. P. Schlumpf, P. Jaouen and F. Quemeneur, Water Res., 2001, 12, 2935-2942.

26 H. De Haan and T. De-Boer, Water Res., 1987, 21, 731-734.

27 J. Peuravuori and K. Pihlaja, Anal. Chim. Acta, 1997, 337, 133149.

28 L. L. Li, T. Jiang, J. L. Yan and N. Guo, Environ. Sci., 2014, 35, 934-941.

29 B. D. Xi and X. He, Spectrosc. Spectral Anal., 2009, 29, 24752479.

30 Y. P. Liu and X. J. Li, Environ. Eng., 2008, 26(4), 89-293.

31 S. L. Huo, B. D. Xi, H. C. Yu, L. S. He, S. L. Fan and H. L. Liu, J. Environ. Sci., 2008, 20, 492-498.

32 C. A. Stedmon, S. Markager and R. Bro, Mar. Chem., 2003, 82(34), 239-254.

33 P. G. Cobel, Mar. Chem., 1996, 51(4), 325-346.

34 J. A. Leenheer and J. Crou, Environ. Sci. Technol., 2003, 37, 18A-26A.

35 Z. Zheng, P. J. He, L. M. Shao and D. J. Lee, Water Res., 2007, 41, 4696-4702.

36 A. Baker and M. Curry, Water Res., 2004, 8, 2605-2613. 